\title{
Deoxygenation of Palmitic Acid to Produce Diesel-like Hydrocarbons over Nickel Incorporated Cellular Foam Catalyst: A Kinetic Study
}

Lilis Hermida ${ }^{1,2}$, H Amani' ${ }^{1}$, Ahmad Zuhairi Abdullah ${ }^{1 *}$ and Abdul Rahman Mohamed ${ }^{1}$

${ }^{1}$ School of Chemical Engineering, Universiti Sains Malaysia, 14300 Nibong Tebal, Penang, Malaysia

${ }^{2}$ Department of Chemical Engineering, Universitas Lampung, Bandar Lampung 35145, Indonesia

\begin{abstract}
Nickel incorporated mesostructured cellular foam (NiMCF) was studied as a catalyst for palmitic acid deoxygenation to primarily synthesize $n$-pentadecane and 1-pentadecene. The kinetic behaviour was tested in a temperature range from 280 to $300^{\circ} \mathrm{C}$. The reaction was found to follow a first order kinetic model with respect to the palmitic acid with an activation energy of $111.57 \mathrm{KJ} / \mathrm{Mol}$. In the reusability study, it was found that the average reduction in palmitic acid conversions was about $40.5 \%$, which indicated the occurrence of catalyst deactivation during the deoxygenation. Fresh and spent catalysts were characterized by means of scanning electron microscope. Energy-dispersive X-ray spectroscopy and X-ray powder diffraction correlate their characteristics with catalytic activity and to identify the main catalyst deactivation mechanism. The catalyst deactivation was mainly due to phase transformation of metallic nickel $\left(\mathrm{Ni}^{0}\right)$ to nickel ion $\left(\mathrm{Ni}^{2+}\right)$ and the deposition of organic molecules on the catalyst during the deoxygenation. Regeneration of spent catalyst successfully reduced the drops in the palmitic acid conversions between the reaction cycles from $40.5 \%$ to $11.3 \%$.
\end{abstract}

Keywords: Mesostructured cellular foam catalyst; Palmitic acid deoxygenation; Microstructure; Diesel-like hydrocarbons; Kinetics

\section{Introduction}

Exhaustion of petroleum oil or crude oil is predicted in the near future [1]. The shortage of crude oil will have global impact on the economy, culture and health of every nation as in this situation; fuel oil prices will go up. The high fuel oil price will induce other commodities or goods to be sold at relatively high prices. Diesel fuel is a kind of fuel oil that is obtained by refining crude oil in petroleum refineries. It has been predicted that the world demand for diesel fuel will grow faster than any other refined oil products in 2035 [2]. Therefore, renewable sources with related technologies should be identified as alternatives. Extensive studies on biofuels production from various renewable feedstocks have been carried out for many years. Among others, catalytic deoxygenation of fatty acids as renewable resources can be a potential technology to synthesize diesel-like hydrocarbons. During fatty acid deoxygenation, $\mathrm{n}$-alkanes and alkenes will be produced through decarboxylation and decarbonylation [3] reactions, respectively;

$$
\begin{aligned}
& \text { Decarboxylation: } \mathrm{C}_{\mathrm{n}} \mathrm{H}_{(2 \mathrm{n}+2)} \mathrm{COO} \rightarrow \mathrm{C}_{\mathrm{n}} \mathrm{H}_{2 \mathrm{n}+2}+\mathrm{CO}_{2} \\
& \text { Decarbonylation: } \mathrm{C}_{\mathrm{n}} \mathrm{H}_{(2 \mathrm{n}+2)} \mathrm{COO} \rightarrow \mathrm{C}_{\mathrm{n}} \mathrm{H}_{2 \mathrm{n}}+\mathrm{CO}+\mathrm{H}_{2} \mathrm{O}
\end{aligned}
$$

The $n$-alkanes and alkenes are hydrocarbons that are similar to those found in crude oil derived diesel fuel [4].

Recently, extensive works have been reported on deoxygenation of various fatty acids to produce diesel-like hydrocarbons. They were carried out either in the presence of solvent or solventless condition using various catalysts such as Pd supported on mesoporous carbon [5-11] or on mesoporous silica [12-14]. Although the catalyst derived from Pd exhibited significant activity in the deoxygenation reactions, they are usually expensive. Ni-based catalysts are more practical on an industrial scale due to their availability and economic feasibility [15-18].

The use of $\mathrm{Al}_{2} \mathrm{O}_{3}$ or $\mathrm{MgO}-\mathrm{Al}_{2} \mathrm{O}_{3}$ supported $\mathrm{Ni}$ catalysts for oleic acid deoxygenation in a batch reactor under solvent free and inert atmosphere conditions have been investigated [19]. Ni supported on mesostructured cellular foam (MCF) silica has been reported to be a more effective catalyst compared to Ni supported on $\mathrm{Al}_{2} \mathrm{O}_{3}$ or SBA-15 catalysts for pyrolytic decomposition of cellulose to produce $\mathrm{H}_{2}$ [20].
This could be due to the larger pores in MCF silica support to minimize the diffusional effects of reactants as well as the products [21,22].

In our earlier work, various $\mathrm{Ni}$ functionalized mesostructured cellular foam (NiMCF) catalysts were used for solventless deoxygenation of palmitic acid at $300^{\circ} \mathrm{C}$ for $6 \mathrm{~h}$ in a semi batch reactor to produce $n$-pentadecane and 1-pentadecene as diesel-like hydrocarbons [23]. The catalysts were synthesized using different structures of MCF silicas prepared under various conditions. It was found that NiMCF catalyst using MCF silica prepared with $9.2 \mathrm{ml}$ of tetra-ethyl-ortho-silicate (TEOS) and subsequently aged for 3 days showed the highest activity for the process. However, no attempt has been made so far to study the reaction kinetic and reusability of the NiMCF catalyst.

In the present study, kinetic of solventless deoxygenation of palmitic acid has been studied in a temperature range from 280 to $300^{\circ} \mathrm{C}$. Reusability of NiMCF catalyst has also been evaluated in the deoxygenation process. The main mechanism for the catalyst deactivation has been successfully elucidated based on SEM, XRD and TGA results.

\section{Experimental}

\section{Preparation of NiMCF catalyst}

NiMCF catalyst was synthesized using MCF silica prepared with 9.2 $\mathrm{mL}$ of tetraethyl orthosilicate (TEOS) and aged for 3 days [23]. Nickel incorporation of into the support was achieved through deposition-

*Corresponding author: Ahmad Zuhairi Abdullah, School of Chemical Engineering Universiti Sains Malaysia, 14300 Nibong Tebal, Penang, Malaysia, Tel:+6045996411; E-mail: chzuhairi@usm.my

Received February 11, 2016; Accepted February 27, 2016; Published March 07 2016

Citation: Hermida L, Amani H, Abdullah AZ, Mohamed AR (2016) Deoxygenation of Palmitic Acid to Produce Diesel-like Hydrocarbons over Nickel Incorporated Cellular Foam Catalyst: A Kinetic Study. J Adv Chem Eng 6: 144. doi:10.4172/20904568.1000144

Copyright: (c) 2016 Hermida L, et al. This is an open-access article distributed under the terms of the Creative Commons Attribution License, which permits unrestricted use, distribution, and reproduction in any medium, provided the original author and source are credited. 
precipitation process and subsequently reduced in hydrogen stream at $550^{\circ} \mathrm{C}$ for $2.5 \mathrm{~h}$ and cooled down under nitrogen flow.

\section{Kinetic of solventless palmitic acid deoxygenation}

Kinetic of solventless palmitic acid deoxygenation was performed in a semi-batch mode in which gaseous products $\left(\mathrm{CO}_{2}, \mathrm{CO}\right.$, etc.) produced during the reaction were continuously removed. The deoxygenation reaction was carried out in a $250 \mathrm{~mL}$ three-necked flask reactor equipped with a magnetic stirring bar, reflux condenser and a tube to pass pure nitrogen flow to reaction mixture. During the reaction, nitrogen stream was used to sweep the evolved gaseous products. The reaction vessel was heated with a stirring hot plate. $6 \mathrm{~g}$ of palmitic acid and $15 \mathrm{wt} \%$ (with respect to palmitic acid) of catalyst amount were then added into the reactor. Before an experiment was started, nitrogen flow was passed through the reaction mixture for 30 min to create an inert reaction environment. Then, the reaction mixture was heated to different temperatures $\left(280-300^{\circ} \mathrm{C}\right)$ and maintained for different reaction times ( 2 to $6 \mathrm{~h}$ ) under rapid stirring. During the reaction, the gaseous products were collected in a gas-sampling bulb. At the end of the reaction, the mixture was allowed to cool to about $100^{\circ} \mathrm{C}$, and then poured through a filter paper to separate the liquid products from the spent catalyst. Analysis of the liquid products was achieved using Agilent Technology 7890A gas chromatograph and then validated using a Perkin Elmer GC-MS system (Clarus 600).

\section{Product analysis}

Gas products in were identified by means of a Shimadzu C11484811134 GC system equipped with a thermal conductivity detector (TCD) and a capillary column. A mixture of standard gases with known composition was injected into the GC to identify each of the gas components based on their retention times. The mixture standard gas consisted of $30 \mathrm{vol} \% \mathrm{CO}_{2}, 30 \mathrm{vol} \% \mathrm{CO}, 30 \mathrm{vol} \% \mathrm{H}_{2}$ and $10 \mathrm{vol} \% \mathrm{Ar}$. It should be noted that the palmitic acid conversion and the desired product selectivity were based on the liquid-phase concentrations of the products. The gas-phase analyses were performed only for the confirmation of the presence of $\mathrm{CO}_{2}$ and $\mathrm{CO}$ in the gaseous products.

Meanwhile, liquid product was collected and analyzed by means of an Agilent Technology 7890A GC system equipped with a flame ionization detector and a non-polar capillary column (GsBP-5). The detector and injector temperatures were set at $280^{\circ} \mathrm{C}$ and $250^{\circ} \mathrm{C}$, respectively. The column temperature was set at $135^{\circ} \mathrm{C}$ for $1 \mathrm{~min}$ and was then programmed at $15^{\circ} \mathrm{C} / \mathrm{min}$ to $290^{\circ} \mathrm{C}$, and it was maintained constant at this temperature for $2 \mathrm{~min} .20 \mu \mathrm{L}$ sample was dissolved in $200 \mu \mathrm{L}$ hexane, and then a direct injection into the gas chromatograph was carried out. The 1-pentadecane $\left(\mathrm{CH}_{3}\left(\mathrm{CH}_{2}\right)_{13} \mathrm{CH}_{3}\right)$ was used as standard to identify substances in a liquid product and to create calibration curves. The calibration curves were used to determine the concentration of substances in the liquid product. Calibration curve was generated using a series of chemical standards with known concentrations. Palmitic acid conversion, product selectivity and product yield were calculated according to Fu et al. [24] using Equations (3), (4) and (5), respectively.

$$
\begin{aligned}
& \text { Conversion \%,C }=\frac{\left[\mathrm{C}_{\mathrm{PA}, 0}\right]-\left[\mathrm{C}_{\mathrm{PA}, \mathrm{t}}\right]}{\left[\mathrm{C}_{\mathrm{PA}, 0}\right]} \times 100 \% \\
& \text { Selectivity } \%, \mathrm{~S}=\frac{\left[\mathrm{C}_{\mathrm{PA}, \mathrm{t}}\right]}{\left[\mathrm{C}_{\mathrm{PA}, 0}\right]-\left[\mathrm{C}_{\mathrm{PA}, \mathrm{t}}\right]} \times 100 \%
\end{aligned}
$$

Yield $\%=\mathrm{C} \times \mathrm{S} \times 100 \%$

where, $\left[\mathrm{C}_{\mathrm{PA}, 0}\right]=$ Concentration of palmitic acid before reaction

$$
\left[\mathrm{C}_{\mathrm{PA}, \mathrm{t}}\right]=\text { Concentration of palmitic acid after reaction }
$$$$
\left[\mathrm{C}_{\mathrm{P}, \mathrm{t}}\right]=\text { Concentration of a product (n-pentadecane }
$$
1-pentadecene) after reaction

\section{Reusability study of NiMCF catalyst}

For reusability study of the catalyst, fresh NiMCF catalyst with amount 15 wt.\% (with respect to palmitic acid) was used for the solventless deoxygenation of palmitic acid at $300^{\circ} \mathrm{C}$ for $2,3,4,5$ and $6 \mathrm{~h}$. After the experiment, the spent NiMCF catalyst was filtered out from the catalytic reaction mixture, washed thoroughly with dichloromethane, and then dried at $100^{\circ} \mathrm{C}$ overnight. Then, the washed spent catalyst was directly reused for the following deoxygenation runs using the same procedure.

Meanwhile, in the regeneration of catalyst, the washed spent catalyst was re-reduced under $\mathrm{H}_{2}$ flow at $550^{\circ} \mathrm{C}$ for $2.5 \mathrm{~h}$ to regenerate it. After that, the spent catalyst was reused for the next deoxygenation run using the same procedure. The regenerated catalyst was characterized by means of TGA, SEM and XRD analyses. For comparison, spent NiMCF catalyst without regeneration was also characterized using the same analytical method.

\section{Characterization of NiMCF catalyst}

The SEM images were captured using a Leo Supra $50 \mathrm{VP}$ field emission SEM. Before observations were made at room temperature, the samples were coated with high purity gold for electron reflection at a thickness of $20 \mathrm{~nm}$ by using a Polaron SC 515 Sputter Coater. Then, samples were mounted on aluminium stubs with double-sided adhesive tape for the observations carried out at a magnification of $50 \mathrm{kX}$.

$\mathrm{X}$-ray diffraction (XRD) analysis was performed using a Siemens 2000X system to obtain XRD patterns of fresh, spend and regenerated catalysts in order to identify the different phases in the catalysts. The $\mathrm{X}$-ray diffraction pattern was recorded using $\mathrm{Cu}-\mathrm{Ka}$ radiation at $2 \theta$ angles ranging from $10-100^{\circ} \mathrm{C}$. The TGA was carried out to observe the change in weight of the catalyst sample as it was heated in a certain temperature range. The thermal gravimetric analyzer unit coupled with a TG controller (TAC 7/DX) was supplied by Perkin-Elmer, USA. About $5 \mathrm{mg}$ of catalyst sample was heated from $31-840^{\circ} \mathrm{C}$ at a heating rate of $10^{\circ} \mathrm{C} / \mathrm{min}$ and an airflow rate of $25 \mathrm{ml} / \mathrm{min}$.

\section{Results and Discussion}

\section{Mechanisme of palmitic acid deoxygenation over NiMCF catalyst}

In this study, the catalyst used was in powder form as obtained from the preparation method. Attempt to measure the particle sizes was not done bearing in mind that the catalyst particles were visibly reduced to even smaller sizes during the reaction under continuous mixing for up to $6 \mathrm{~h}$. The stirring speed was set at about $250 \mathrm{rpm}$. Under such conditions, no significant external mass transfer effect was expected as generally reported in literatures [10-13].

Solventless palmitic acid deoxygenation over NiMCF catalyst in a semi batch reactor at $300^{\circ} \mathrm{C}$ produced mainly $n$-pentadecane and 1 -pentadecene (Figure 1). In this reaction, $n$-pentadecane and 1-pentadecene were the predominant products so that the concentrations of both products were high at the end of the reaction. In the first $3 \mathrm{~h}$ of reaction, palmitic acid was converted 


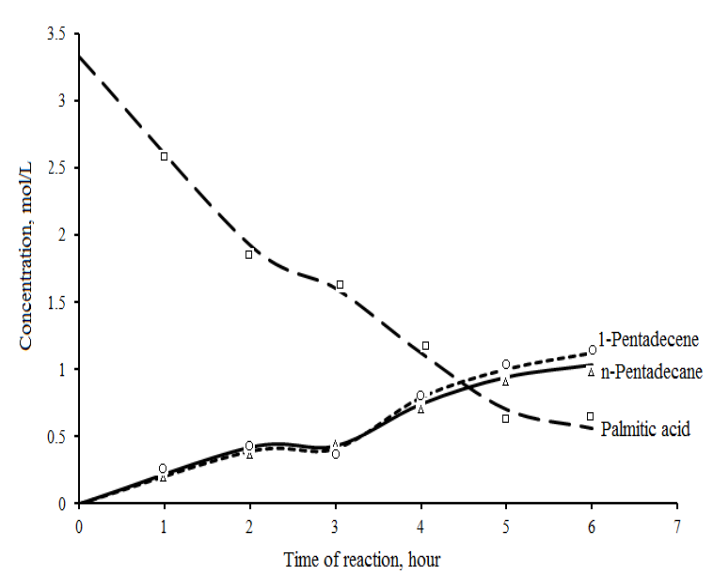

Figure 1: Solventless palmitic acid deoxygenation over NiMCF catalyst at $300^{\circ} \mathrm{C}$ with catalyst loading of $15 \mathrm{wt} \%$.

into $n$-pentadecane and 1-pentadecene in which concentration of $n$-pentadecane was slightly higher than that of 1 -pentadecene. This indicated that decarboxylation reaction was a more favoured reaction than decarbonylation reaction during this period. On the other hand, at reaction times longer than $3 \mathrm{~h}$, concentrations of 1-pentadecene were usually higher than those of $n$-pentadecane. This observation gave the indication that decarbonylation reaction was the more dominant reaction compared to decarboxylation reaction. The lower $n$-pentadecane concentration was ascribed to the higher formation of CO gas that could inhibit the palmitic acid decarboxylation. CO gas which is a by-product from palmitic acid decarbonylation is poison to the catalyst in the decarboxylation reaction [25]. The activity of this catalyst was comparable with that reported by Roh et al. [19] using Ni/ $\mathrm{MgO}-\mathrm{Al}_{2} \mathrm{O}_{3}$ catalyst.

$\mathrm{CO}_{2}$ and $\mathrm{CO}$ gases were detected in gaseous product through GC equipped with TCD detector. Meanwhile, $n$-pentadecane and 1-pentadecene were also detected in liquid products through GC-MS analysis. Besides $n$-pentadecane and 1-pentadecene, other products such as cyclopentadecane, ketone, etc. were also present at small quantities in the liquid products. This indicated that deoxygenation of palmitic acid acids over NiMCF catalyst in this study occurred not only through decarboxylation and decarbonilation reactions, but other reactions could also occur. Based on the reaction products, reaction pathways of solventless palmitic acid deoxygenation reaction could be proposed. Palmitic acid is first deoxygenated through decarboxylation reaction to produce $n$-pentadecane and $\mathrm{CO}_{2}$ and through decarbonylation reaction to produce 1-pentadecene, $\mathrm{CO}$ and $\mathrm{H}_{2} \mathrm{O}$. Besides that, 1-pentadecene can also be produced through dehydrogenation of $n$-pentadecane. Moreover, a part of palmitic acid is converted into $n$-hexadecane $\left(\mathrm{C}_{16} \mathrm{H}_{34}\right)$ through hydrogenation reaction [5].

\section{Kinetic of solventless deoxygenation of palmitic acid over NiMCFcatalyst}

Kinetic study of palmitic acid deoxygenation over the synthesized NiMCF catalyst was investigated at three different temperatures (280, 290 and $\left.300^{\circ} \mathrm{C}\right) .6 \mathrm{~g}$ of palmitic acid and catalyst loading of 15 wt $\%$ was used in all the experiments. The kinetic model of oleic acid under inert atmosphere is suggested to follow first order with respect oleic acid [26]. Hence, the first order kinetic model for palmitic acid deoxygenation can be expressed as follows;

$$
\text { Rate }=\frac{-\mathrm{d}\left[\mathrm{C}_{\mathrm{PA}}\right]}{\mathrm{dt}}=\mathrm{k}\left[\mathrm{C}_{\mathrm{PA}}\right]
$$

where, $k$ is the rate constant, $\mathrm{t}$ is reaction time and $\left[\mathrm{C}_{\mathrm{PA}}\right]$ is the concentration of palmitic acid. In the kinetic study, the change in the palmitic acid concentration with the time was followed from the start of the reaction, $\left[\mathrm{CP}_{\mathrm{A}}\right]_{0}$ at $\mathrm{t}=0$ to $\left[\mathrm{C}_{\mathrm{PA}}\right]_{\mathrm{t}}$ at time $\mathrm{t}$. These are the limits between which integration is performed. Upon integration and rearrangement, the final equation obtained is;

$$
\ln =\frac{\left[{ }^{\mathrm{C}_{\mathrm{PA}}}\right]_{\mathrm{t}}}{\left[\mathrm{C}_{\mathrm{PA}}\right]_{0}}=-\mathrm{kt}
$$

The experimental results obtained in this study are shown in Figure 2. As can be seen in the figure, the increase in temperature reaction resulted in an increase in the disappearance of palmitic acid concentration. This indicated that the temperature had positive effect in accelerating the reaction rate. Since the kinetic model of the palmitic acid deoxygenation is assumed to follow a first order model with respect palmitic acid, Equation (7) can be used. Figure 2 shows the plot of Equation (7) which $\ln \left[\mathrm{C}_{\mathrm{PA}_{\mathrm{t}}}\right]_{\mathrm{t}} /\left[\mathrm{C}_{\mathrm{PA}}\right]_{0}$ is plotted against the reaction times. All the experimental data obtained for the palmitic acid deoxygenation experiments are found to be in good agreement with the Equation 7 due to the high value of correlation coefficient $\left(\mathrm{R}^{2}\right.$ are above 0.95) for all the straight lines. This indicates that the assumption that was used in this analysis was valid.

The integrated form of the rate law allows us to find the concentration of palmitic acid at any time after the start of the reaction. The slopes of the straight lines obtained by plotting $\ln \left[\mathrm{C}_{\mathrm{PA}_{\mathrm{t}}}\right]_{\mathrm{t}} /\left[\mathrm{C}_{\mathrm{PA}}\right]_{0}$ versus the reaction time give $-k$, as can be seen in Figure 2. The reaction rate constants $(\mathrm{k})$ are summarized in Table 1 . As can be seen in the table, the increase in temperature resulted in the increase in the reaction rate constant. This was because mobility of reactant molecules was higher when the temperature was increased. The higher mobility of palmitic acid molecules made it easier for the molecules to reach the metallic nickel that might be located in the cell or the window pores in the NiMCF catalyst. The metallic nickel sites were the active sites for catalyzing the palmitic acid deoxygenation to produce diesel-like hydrocarbons of $n$-pentadecane and pentadecene [19].

Phenomenon of molecular diffusion is generally relevant in most liquid phase reactions involving porous catalysts. Furthermore, a rather viscous liquid (palmitic acid) was used as the reactant in this reaction. However, it has been reported that catalyst having a minimum average

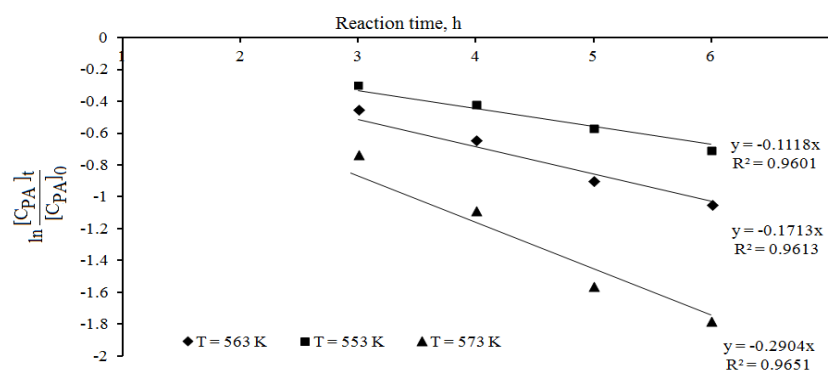

Figure 2: Plot of $\ln [\mathrm{CPA}] \mathrm{t} /[\mathrm{CPA}]$ versus reaction time at various temperature.

\begin{tabular}{|c|c|}
\hline Temperature (K) & Specific rate constant, $\left.\mathbf{k}_{\mathbf{s}} \mathbf{( h}^{-\mathbf{1}}\right)$ \\
\hline 553 & 0.1118 \\
\hline 563 & 0.1713 \\
\hline 573 & 0.2904 \\
\hline
\end{tabular}

Table 1: Specific rate constants for the first order kinetic model. 
pore size of $20 \AA$ is required for liquid phase reactions to effectively avoid internal diffusion effect of the reactants and products [22]. In this study, structure of the NiMCF catalyst with large cell size (234 $\AA$ ) and window pore size (90 $)$ ) in the NiMCF catalyst should favour diffusion of the reactant and product molecules [23]. Thus, the effect of internal diffusion limitation should be negligible considering the small particle sizes of the catalyst. As such, reactant molecules reacted faster in the catalyst when mobility of reactant and product molecules was higher. Feature of molecular diffusions in three-dimensional structure of NiMCF catalyst together with its cell and window pores can be seen in Figure 3.

The rate constant, $k$, is related to the reaction temperature by the Arrhenius equation. The equation takes into account the rate constant of chemical reactions $\left(\mathrm{k}_{\mathrm{s}}\right)$, reaction temperature $(\mathrm{T})$, the activation energy $\left(\mathrm{E}_{\mathrm{A}}\right)$, the pre-exponential factor $(\mathrm{A})$ and the universal gas constant $\mathrm{R}$. The Arrhenius equation is a relationship for the dependence of a reaction rate on temperature;

$$
\ln k_{s}=\ln \mathrm{A}-\mathrm{E}_{\mathrm{A}} / \mathrm{RT}
$$

where; $k_{s}=$ specific rate constant, $\mathrm{h}^{-1}$

$\mathrm{A}=$ pre-exponential factor, $\mathrm{h}^{-1}$

$\mathrm{E}_{\mathrm{A}}=$ activation energy, $\mathrm{J} / \mathrm{mol}$

\section{$\mathrm{R}=$ gas constant $=8.314 \mathrm{~J} / \mathrm{mol} . \mathrm{K}$}

The activation energy, $\mathrm{E}_{\mathrm{A}}$, and pre-exponential factor, $\mathrm{A}$, can be obtained by plotting ln $k_{s}$ versus $1 / \mathrm{T}$. The plot should produce a straight line in which a slope and intercept equal to $-\mathrm{E}_{\mathrm{A}} / R$ and $\ln A$, respectively. On the basis of data obtained from Table 1 , a plot of $\ln$ $\mathrm{k}_{\mathrm{s}} \mathrm{vs} 1 / \mathrm{T}$ yields a straight line with high value of correlation coefficient $\left(\mathrm{R}^{2}>0.95\right)$. This result shows that the reaction rate constant follows the Arrhenius law, as can be seen in Figure 4. The value of activation energy $\left(\mathrm{E}_{\mathrm{A}}\right)$ and pre-exponential factor $(\mathrm{A})$ are calculated to be $111.565 \mathrm{~kJ} /$ mol and $38 \times 10^{8} / \mathrm{h}$, respectively. The value of EA for this reaction is relatively lower than that reported in literature for $\mathrm{Ni} / \mathrm{MgO}-\mathrm{Al}_{2} \mathrm{O}_{3}(123$ $\mathrm{kJ} / \mathrm{mol}$ ) to indicate higher activity of the catalyst used in this study [19].

With the kinetic parameters $\left(\mathrm{E}_{\mathrm{A}}, A\right.$ and $\left.k\right)$ that were obtained, mathematical model of rate expressions can be constructed as follows,

$$
-\mathrm{r}_{\mathrm{PA}}=38 \times 10^{8} \exp \left(-\frac{111565}{\mathrm{RT}}\right)\left[\mathrm{C}_{\mathrm{PA}}\right] \mathrm{mol}^{-1} \mathrm{~h}^{-1}
$$

The values of palmitic acid concentrations can be calculated using the first order kinetic model using Equation (7). The values of the palmitic acid concentration from the calculation and from the experimental results are presented in Table 2.

A parity plot between the experimental and calculated values of palmitic acid concentration is showed in Figure 5. As can be seen in the figure, the values of the palmitic acid concentration calculated at any time after the start of the reaction are in good agreement with experimental palmitic acid concentrations with a high value of correlation coefficient $\left(\mathrm{R}^{2}>0.95\right)$. It can be concluded from the results that palmitic acid deoxygenation over NiMCF catalyst satisfactorily followed first order kinetic model with respect to palmitic acid.

\section{Reusability study of NiMCF catalyst}

One of the major obstacles in the use of supported metal catalyst in fatty acid deoxygenation for production of diesel-like hydrocarbons is catalyst deactivation. Study of reusability of catalyst is important

for the economic assessment of the catalytic fatty acid deoxygenation process. Through the catalyst reusability study, stability and degree of catalyst deactivation can be examined. In this part of work, reusability of the NiMCF catalyst was studied through experiments in which the NiMCF catalyst after one cycle of use (or spent NiMCF catalyst) was re-used without regeneration for further solventless palmitic acid deoxygenation palmitic cycle. Alternatively, the catalyst was also regenerated as described in section 2.4 and used in the same reaction. Figure 6 shows results of the palmitic acid conversions obtained from various reaction times for the fresh NiMCF and the spent NiMCF catalytst.

As can be seen in Figure 6, palmitic acid conversions decreased after one cycle of use for all reaction times. This indicated the occurrence of significant deactivation of NiMCF catalyst during the palmitic acid

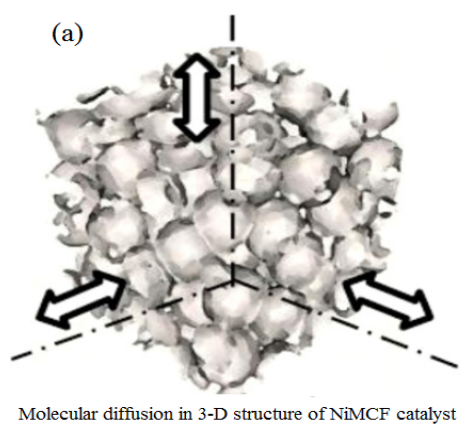

(b)

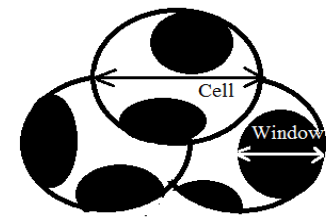

Cell $=234$ Angstrom

Window $=90$ Angstrom

Figure 3: (a) Molecular diffusions in 3-D structure of NiMCF catalyst, (b) cell and window pores in NiMCF catalyst.

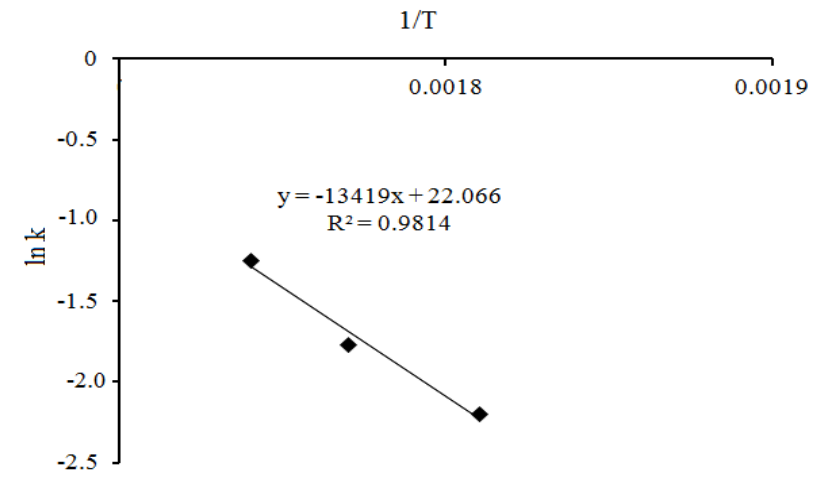

Figure 4: Arrhenius plot for palmitic acid deoxygenation over NiMCF catalyst.

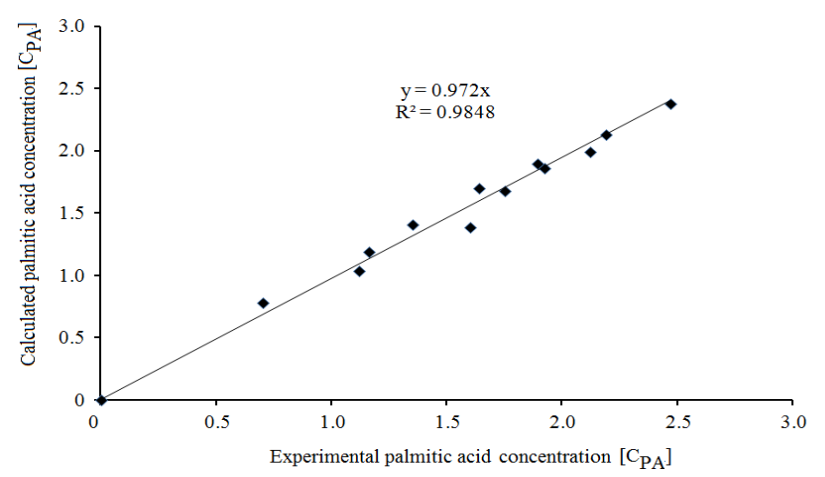

Figure 5: Parity plot between the experimental and calculated values of palmitic acid concentration. 


\begin{tabular}{|c|c|c|c|c|c|c|}
\hline \multirow[t]{2}{*}{ Time (h) } & \multicolumn{2}{|c|}{$\left[\mathrm{C}_{\mathrm{PA}}\right]$ at $553 \mathrm{~K}$} & \multicolumn{2}{|c|}{$\left[\mathrm{C}_{\mathrm{PA}}\right]$ at $563 \mathrm{~K}$} & \multicolumn{2}{|c|}{$\left[\mathrm{C}_{\mathrm{PA}}\right]$ at $573 \mathrm{~K}$} \\
\hline & Experimental & Calculated & Experimental & Calculated & Experimental & Calculated \\
\hline 2 & - & - & - & - & 1.92 & 1.86 \\
\hline 3 & 2.47 & 2.38 & 2.12 & 1.99 & 1.6 & 1.39 \\
\hline 4 & 2.19 & 2.13 & 1.75 & 1.68 & 1.12 & 1.04 \\
\hline 5 & 1.89 & 1.9 & 1.35 & 1.41 & 0.7 & 0.78 \\
\hline 6 & 1.64 & 1.7 & 1.16 & 1.19 & 0.56 & 0.58 \\
\hline
\end{tabular}

Table 2: Values of experimental palmitic acid concentrations versus calculated ones.

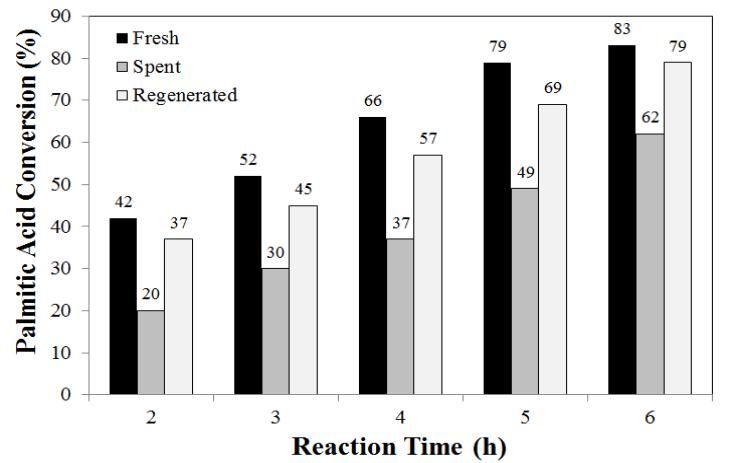

Figure 6: Comparison between solven less palmitic acid deoxygenation over fresh NiMCF, spent and regenerated NiMCF catalyst.

deoxygenation process after the first cycle. The catalyst deactivation caused reductions on the fatty acid conversion. The spent catalyst achieved palmitic acid conversion of $20 \%$ at a reaction time of $2 \mathrm{~h}$. Meanwhile, fresh catalyst achieved palmitic acid conversion of $42 \%$ at a reaction time of $2 \mathrm{~h}$. Thus, the reduction in palmitic acid conversion at $2 \mathrm{~h}$ of reaction is $52.8 \%$. Meanwhile, reduction of palmitic acid conversion at $3,4,5$ and $6 \mathrm{~h}$ of reaction time were $42.3 \%, 43.9 \%, 38.0 \%$ and $25.3 \%$, respectively. Hence, average reduction of palmitic acid conversion using spent catalyst was $40.5 \%$.

Figure 6 also shows palmitic acid conversions obtained by using the fresh NiMCF and regenerated NiMCF catalysts in the solventless palmitic acid deoxygenation using the same operating conditions. As can be seen, palmitic acid conversions using the regenerated catalyst were slightly lower than those using fresh catalyst for all reaction times. Reduction of palmitic acid conversion at 2, 3, 4, 5 and $6 \mathrm{~h}$ of reaction time were $11.9 \%, 13.5 \%, 13.6 \%, 12.7 \%$ and $4.8 \%$, respectively. The average reduction of palmitic acid conversion using a semi-batch reactor was $11.3 \%$.

Despite significant reduction in palmitic acid conversion, the values achieved by the regenerated catalyst were higher than those achieved by the spent catalyst without regeneration. By regenerating the spent catalyst, the extent on the drop in palmitic acid conversion reduced from $40.5 \%$ to $11.3 \%$. This indicated that the regeneration of the spent catalyst using this method could improve the performance of the spent catalyst.

Deactivation of palladium supported on MCF catalyst (PdMCF) has been reported to be severe after one cycle of use for stearic acid deoxygenation in the presence of dudeen as solvent [14]. Almost no conversion of stearic acid was achieved by spent PdMCF catalyst in the deoxygenation reactions at reaction times from 0 until $6 \mathrm{~h}$. PdMCF catalyst was mainly deactivated by significant organic deposition on the catalyst during the reaction. Other deactivation mechanism i.e., oxidation of metallic palladium and agglomeration of palladium particles on the catalyst was insignificant. The catalyst deactivation sources were elucidated based on results of various characterization tests. Regeneration of the spent PdMCF catalyst was also carried out by sequential hot extractions with solvents tetrahydrofuran (THF), hexane and dichloromethane (DCM) followed by re-reduction process at $300^{\circ} \mathrm{C}$. The regenerated catalyst showed a 19 -fold increase in decarboxylation activity as compared to the spent PdMCF catalyst.

In order to identify mechanism of catalyst deactivation, several catalyst characterization methods such as XRD, SEM and TGA were performed. Evaluation of the deactivation mechanism involved comparison of the physical and chemical characteristics for the fresh and spent NiMCF catalysts. However, excessive discussion on the catalyst characteristics is avoided as in this liquid phase reaction, changes in the characteristics of the catalyst could significantly occur during the reaction and characteristics that are obtained ex-situ such as surface characteristics etc. could give misleading information on the reaction. In this study, the catalyst was recovered after the reaction by filtration and washed with organic solvents followed by drying. Unfortunately, complete removal of organic substances from the surface of the catalyst was not achieved. These organics would decompose during the degassing step (at $300^{\circ} \mathrm{C}$ ) of surface analysis through nitrogen adsorption-desorption to cause errors in the results. Thus, attempts to measure the surface area after the reaction were unsuccessful. Figure 7 compares the characteristic of the fresh, spent and regenerated NiMCF catalysts by means of an XRD analysis method. For the spent catalyst sample, XRD pattern displays a peak at $2 \theta=23^{\circ}$ that is attributed to the presence of amorphous silica. Besides that, the XRD pattern displays peaks at $2 \theta=33$ and $60^{\circ}$ that are characteristic of nickel ions $\left(\mathrm{Ni}^{2+}\right)$ that could be in the form of nickel phylosilicates [27].

Furthermore, peak at $2 \theta=44^{\circ}$ attributed to metallic nickel particles is almost not detected in the spent catalyst sample. This indicated that metallic nanoparticle sintering, agglomeration and ripening that are common nanoparticles phenomena were not the main cause of deactivation in this system. In fact, higher peaks at $2 \theta=33$ and $60^{\circ}$ in the XRD pattern of the spent catalyst compared to those in the pattern of fresh catalyst could be due to evolvement of water vapour that oxidized the metallic nickel nanoparticles $\left(\mathrm{Ni}^{0}\right)$ during the palmitic acid deoxygenation so that they changed into nickel ions $\left(\mathrm{Ni}^{2+}\right)$ that could be in the form of nickel phylosilicate or nickels oxide phases.

Water vapour is a by-product in palmitic acid decarbonylation and hydrogenation. It could also be produced through water gasshift reaction and methanation $[28,29]$ in which molecules of $\mathrm{H}_{2}$ from dehydrogenation reactions react with molecules of other gaseous products, i.e., $\mathrm{CO}_{2}$ and $\mathrm{CO}$ (by-products from decarboxylation and decarbonylation), as given in the following reactions;

$$
\begin{aligned}
& \text { Water gas-shift reaction: } \mathrm{CO}_{2}+\mathrm{H}_{2} \otimes \mathrm{CO}+\mathrm{H}_{2} \mathrm{O} \\
& \text { Methanation: } 2 \mathrm{H}_{2}+\mathrm{CO} \rightarrow \mathrm{CH}_{4}+\mathrm{H}_{2} \mathrm{O} \\
& \text { Methanation: } 4 \mathrm{H}_{2}+\mathrm{CO}_{2} \rightarrow \mathrm{CH}_{4}+2 \mathrm{H}_{2} \mathrm{O}
\end{aligned}
$$

It has been reported in literature that the presence of water vapor reduced the activity iron catalyst in Fischer-Tropsch reaction due to 


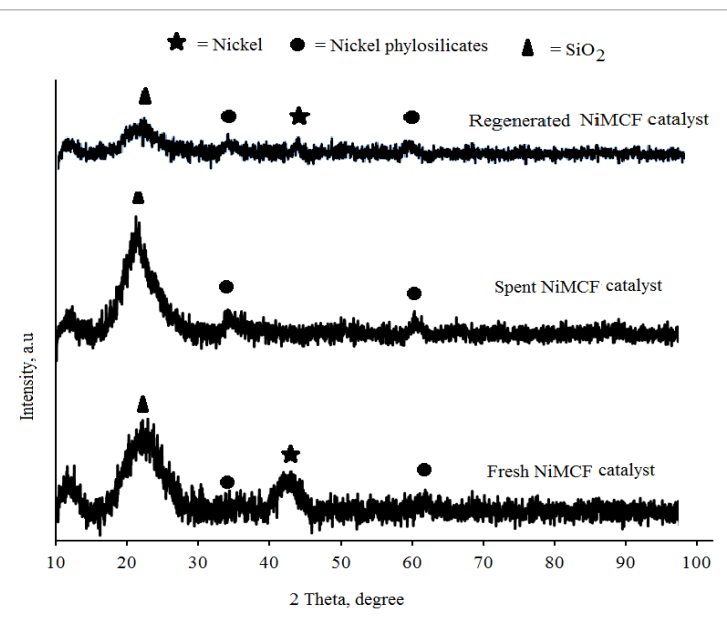

Figure 7: XRD patterns of fresh, spent and regenerated NiMCF catalysts.

the oxidation of iron catalyst by water vapor [30]. Meanwhile, nickel catalyst was found to have low activity for hydrocarbon transformation in the presence of water vapour due to oxidation metallic nickel by water vapour [31]. Through the oxidation reaction, metallic nickels in $\mathrm{Ni} / \mathrm{Al}_{2} \mathrm{O}_{3}$ catalyst transformed into nickel ions $\left(\mathrm{Ni}^{2+}\right)$ in the form of nickelous oxide phases that rapidly re-crystallize [32]. This nickel catalyst deactivation mechanism can be applicable to the deactivation of NiMCF catalyst by water vapor in this study.

For the fresh catalyst sample, the presence of metallic nickel particles was clearly detected through the observation on the XRD pattern, as can be seen in Figure 7. The phase transformation from metallic nickel $\left(\mathrm{Ni}^{0}\right)$ into nickel ion $\left(\mathrm{Ni}^{2+}\right)$ reduced the activity of the spent catalyst in the deoxygenation reaction. This caused the decrease in palmitic acid conversion this system. It can be concluded that metallic particles $\left(\mathrm{Ni}^{0}\right)$ in NiMCF catalyst have higher active sites than nickel ion $\left(\mathrm{Ni}^{2+}\right)$ in NiMCF catalyst for the palmitic acid deoxygenation reaction. This result was in agreement with reports that oxide type catalysts such as $\mathrm{MnO}_{3} / \mathrm{C}, \mathrm{MnO} / \mathrm{C}, \mathrm{WO}_{3} / \mathrm{C}, \mathrm{NiOMoO}{ }_{3} / \mathrm{Al}_{2} \mathrm{O}_{3}$ and $\mathrm{V}_{2} \mathrm{O}_{5} / \mathrm{C}$ had lower activities compared to metal type catalysts such as $\mathrm{Ni} / \mathrm{C}, \mathrm{Co} / \mathrm{SiO}_{2}$, $\mathrm{Ni} / \mathrm{SiO}_{2}$ and $\mathrm{Ni} / \mathrm{Al}_{2} \mathrm{O}_{3}$ for deoxygenation of bio-oil [33] and also for deoxygenation of fatty acid methyl ester.

On the basis of the aforementioned characterization results, it is hypothesized that the catalyst deactivation in this study could be attributed to organic molecules derived from reactant and products as well as small deposits of coke on the catalyst. Besides that, phase transformation from metallic nickel $\left(\mathrm{Ni}^{0}\right)$ into to nickel ion $\left(\mathrm{Ni}^{2+}\right)$ was also responsible for the catalyst deactivation. Therefore, regeneration of the spent catalyst was then carried out. Furthermore, the regenerated catalyst was characterized by means of XRD and SEM. Figure 7 also shows the comparison between XRD pattern of spent NiMCF catalyst and that of regenerated NiMCF catalyst.

The XRD pattern of the regenerated catalyst displayed the presence of peak at $2 \theta=44^{\circ}$ that is characteristics to the metallic nickel particles. However, peaks at at $2 \theta=33$ and $60^{\circ}$ that are characteristics of the nickel phylosilicates are still present with considerable intensities in the regenerated catalyst. This indicated that not all nickel phylosilicate was reduced into metallic nickel after the re-reduction process. The re-reduction process was carried out at $550^{\circ} \mathrm{C}$ for $2.5 \mathrm{~h}$ in this study. The unreduced nickel phylosilicate was probably due to very high interactions between nickel phylosilicates and MCF silica. As such, in order to reduce the more nickel phylosilicate, the re-reduction process should be carried out at higher temperatures and/or for a longer period.
In order to identify the possibility of catalyst deactivation due to deposition of organic molecules on the spent catalyst, weight loss, thermal behaviour and structural destruction of the spent catalyst were investigated using TGA analysis method. Figure 8 shows a TGA thermo gram of the spent catalyst together with the first derivative whether its weight change from the TGA test. A decomposition region occurred from temperatures of around 250 to $600^{\circ} \mathrm{C}$. The derivative of the thermo gram clearly exposes this inflection with maximum peak at around $400^{\circ} \mathrm{C}$. The decomposition of the spent catalyst in this region could be attributed to the removal of organic components that were deposited on the catalyst. Removal of organic components deposited in spent Pd functionalized MCF catalyst at the same temperature region was reported in the literature [14].

Morphologies of the fresh and spent NiMCF catalyst were examined by means of SEM. The SEM image results are shown in Figure 9. The SEM image of the spent catalyst clearly confirms layered structures in the spent catalyst. The layered structures contained nickel ions $\left(\mathrm{N}^{2+}\right)$ that could be in the form of nickel phylosilicate. The SEM image of the spent catalyst also confirmed that the spent catalyst had fewer porous structures compared to the fresh catalyst. Meanwhile, the SEM image of the fresh catalyst reveals high porous structures with Nano worm structures of nickel nanoparticles on the MCF silica.

Figure 9 also shows comparison between SEM images of the fresh NiMCF catalyst and regenerated NiMCF catalysts. The SEM image of the regenerated catalyst confirmed nickel nanoparticles in the form of Nano worm structures with sizes of around $19 \mathrm{~nm}$. The structures in the regenerated catalyst were almost the same with those in fresh catalyst but the nickel nanoparticle sizes in the regenerated catalyst were slightly larger than those in fresh catalyst. Besides that, mesoporous structures in the regenerated catalyst were slightly lower than those in fresh catalyst. Nevertheless, the regenerated catalyst regained nearly all of lost porosity and metallic nickel particles after the sufficient removal of deposited organic molecules and followed by the re-reduction process.

\section{Conclusion}

Kinetic of solventless palmitic acid deoxygenation over nickel functionalized mesostructured cellular foam catalyst (NiMCF) to selectively synthesize $n$-pentadecane and 1-pentadecene (diesel-like hydrocarbons) was successfully studied in a temperature range from 280 to $300^{\circ} \mathrm{C}$. The deoxygenation reaction satisfactorily followed a first order kinetic with an activation energy of $111.57 \mathrm{~kJ} / \mathrm{mol}$. From the reusability studies of the NiMCF catalyst, it was found that palmitic acid conversions significantly decreased after one cycle of use for all reaction times which suggested the occurrence of catalyst deactivation. The average reduction of palmitic acid conversion was about $40.5 \%$. Based on characterizations of the spent catalyst, the main cause for

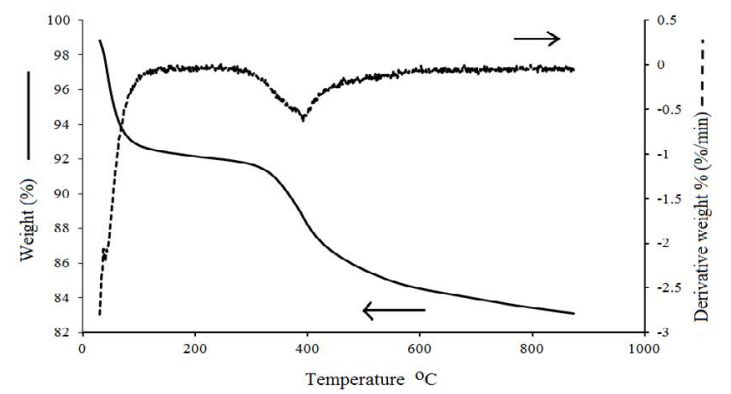

Figure 8: TGA profile (solid line) with its derivative profile (broken line) for spent NiMCF catalyst. 
Citation: Hermida L, Amani H, Abdullah AZ, Mohamed AR (2016) Deoxygenation of Palmitic Acid to Produce Diesel-like Hydrocarbons over Nickel Incorporated Cellular Foam Catalyst: A Kinetic Study. J Adv Chem Eng 6: 144. doi:10.4172/2090-4568.1000144

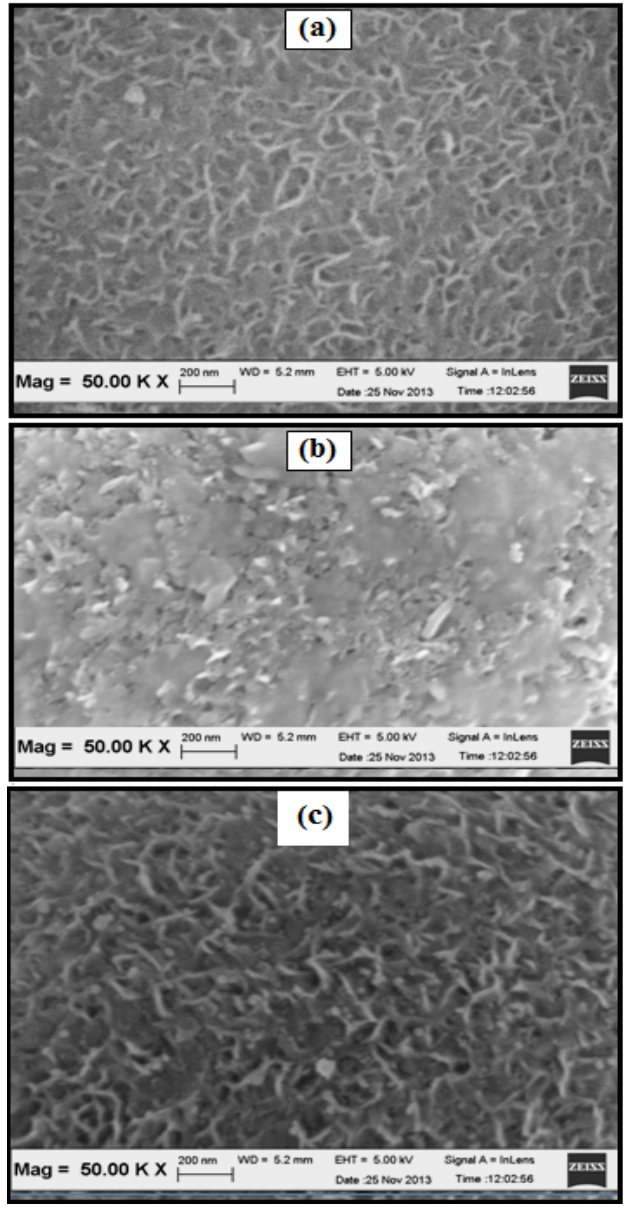

Figure 9: Comparison between SEM images of (a) fresh NiMCF, (b) spent NiMCF and (c) regenerated NiMCF catalyst obtained from catalytic deoxygenation in a semi-batch reactor.

the deactivation sources was found to be the phase transformation of metallic nickel $\left(\mathrm{Ni}^{0}\right)$ into to nickel ion $\left(\mathrm{Ni}^{2+}\right)$ and the deposition of organic molecules on the NiMCF catalyst during the palmitic deoxygenation. Regeneration of the spent improved the performance the spent catalyst in which the extent of drop in the palmitic acid conversion could be reduced from $40.5 \%$ to $11.3 \%$.

\section{Acknowledgments}

The authors gratefully acknowledge a Research University grant (No. 814181) from Universiti Sains Malaysia and a Science fund grant (6013381) from MOSTI Malaysia to support this study.

\section{References}

1. Amani H, Ahmad Z, Asif M, Hameed BH (2014) Transesterification of waste cooking palm oil by MnZr with supported alumina as a potential heterogeneous catalyst. J Ind Eng Chem 20: 4437-4442.

2. Amani H, Ahmad Z, Hameed BH (2014) Synthesis of fatty acid methyl esters

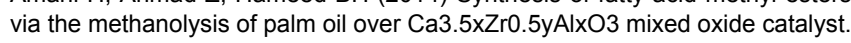
Renewable Energy 66: 680-685.

3. Ayodelea OB, Hamisu U, Jibril MY, Uemurad WM, Dauda AW (2015) Hydrodeoxygenation of oleic acid into $n$ - and iso-paraffin biofuel using zeolite supported fluoro-oxalate modified molybdenum catalyst: Kinetics study. J Taiwan Inst Chem Eng 50: 142-152.

4. Matzen M, Alhajji M, Yasar D (2015) Demirel Technoeconomics and Sustainability of Renewable Methanol and Ammonia Productions Using Wind Power-based Hydrogen. J Adv Chem Eng 5: 128.
5. Ang GT, Tan KT, Lee KT (2015) Supercritical and Superheated Technologies: Future of Biodiesel Production. J Adv Chem Eng 5: e106.

6. Moore M, Herrell B, Counce R, Watson J (2015) A Hierarchical Procedure for Synthesis of a Base Case Solid Oxide Fuel Cell System in Aspen HYSYS. J Adv Chem Eng 5: 129

7. Lee SP, Ramli A (2013) Methyl oleate deoxygenation for production of diese fuel aliphatic hydrocarbons over Pd/SBA-15 catalysts. Chem Cent J 7: 149.

8. Amani H, Ahmad Z, Hameed BH (2014) Highly active alumina-supported Cs- Zr mixed oxide catalysts for low-temperature transesterification of waste cooking oil. Appl Catal A 487: 16-25.

9. Maki-Arvela P, Rozmyszowicz B, Lestari S, Simakova O, Eranen K, et al (2011) Catalytic deoxygenation of tall oil fatty acid over palladium supported on mesoporous carbon. Energy Fuels 25: 2815-2825.

10. Amani $\mathrm{H}$, Asif M, Hameed $\mathrm{BH}$ (2016) Transesterification of waste cooking palm oil and palm oil to fatty acid methyl ester using cesium-modified silica catalyst J Taiwan Inst Chem Eng 58: 226-234.

11. Mansur AA, Pannirselvam M, Al-Hothaly KA, Adetutu EM, Ball AS (2015) Recovery and Characterization of Oil from Waste Crude Oil Tank Bottom Sludge from Azzawiya Oil Refinery in Libya. J Adv Chem Eng 5: 118.

12. Albrecht KO, Hallen RT (2011) A Brief Literature Overview of Various Routes to Biorenewable Fuels from Lipids for the National Alliance for Advanced Biofuels and Bio-products (NAABB) Consortium. Department of Energy, Pacific Northwest National Laboratory.

13. Sivula L, llander A, Väisänen A, Rintala J (2010) Weathering of gasification and grate bottom ash in anaerobic conditions. J Hazard Mater 174: 344-351.

14. Ping EW, Pierson J, Wallace R, Miller JT, Fuller TF, et al. (2011) On the nature of the deactivation of supported palladium nanoparticle catalysts in the decarboxylation of fatty acids. Appl Catal A 396: 85-90.

15. Kho ET, Scott J, Amal R (2016) Ni/TiO2 for low temperature steam reforming of methane. Chemical Engineering Science 140: 161-170.

16. Wang J, Lu AH, Li M, Zhang W, Chen YS, et al. (2013) Thin porous alumina sheets as supports for stabilizing gold nanoparticles. ACS Nano 7: 4902-4910.

17. Haitham MA, Bernd H (2015) Template-Assisted Synthesis of Metal Oxide Hollow Spheres Utilizing Glucose Derived-Carbonaceous Spheres As Sacrificial Templates. J Adv Chem Eng 5: 116.

18. Olutoye MA, Wong SW, Chin LH, Amani H, Asif M, et al. (2016) Synthesis of fatty acid methyl esters via the transesterification of waste cooking oil by methanol with a barium-modified montmorillonite K10 catalyst. Renewable Energy 86: 392-398.

19. Roh HS, Eum IH, Jeong DW, Yi BE, Na JG, et al. (2011) The effect of calcination temperature on the performance of $\mathrm{Ni} / \mathrm{MgO}-\mathrm{Al}_{2} \mathrm{O}_{3}$ catalysts for decarboxylation of oleic acid. Catal Today 164: 457-460

20. Zhao M, Yang X, Church TL, Harris AT (2012) Novel CaO-SiO2 sorbent and bifunctional $\mathrm{Ni} / \mathrm{Co}-\mathrm{CaO} / \mathrm{SiO} 2$ complex for selective $\mathrm{H} 2$ synthesis from cellulose. Environ Sci Technol 46: 2976-2983.

21. Lam MK, Uemura Y (2015) The Potential of Gamma-Valerolactone (GVL) Production from Oil Palm Biomass. J Adv Chem Eng 5: e105.

22. Mahmud CK, Haque MdA, Chowdhury AMS, Ahad MA, Gafur MdA (2014) Preparation and Characterization of Polyester Composites Reinforced with Bleached, Diospyros perigrina (Indian persimmon) Treated and Unbleached Jute Mat. J Adv Chem Eng 4: 114.

23. Hermida L, Abdullah AZ, Mohamed AR (2013) Nickel functionalized mesostructured cellular foam (MCF) silica as a catalyst for solventless deoxygenation of palmitic acid to produce diesel-like hydrocarbons. In Mendez-Vilas A (Ed) Materials and Processes for Energy: Communicating Current Research and Technological Developments. Brown Walker Press, Boca Raton, USA.

24. Morales G, Melero JA, Iglesias J, Paniagua M (2014) Advanced Biofuels from Lignocellulosic Biomass. J Adv Chem Eng 4: e101.

25. Immer JG (2010) Liquid-phase deoxygenation of free fatty acids to hydrocarbons using supported palladium catalysts. North Carolina State University, Raleigh.

26. Díaz L, Brito A (2014) FFA Adsorption from Waste Oils or Non-Edible Oils onto an Anion-Exchange Resin as Alternative Method to Esterification Reaction Prior to Transesterification Reaction for Biodiesel Production. J Adv Chem Eng 4: 105. 
Citation: Hermida L, Amani H, Abdullah AZ, Mohamed AR (2016) Deoxygenation of Palmitic Acid to Produce Diesel-like Hydrocarbons over Nickel Incorporated Cellular Foam Catalyst: A Kinetic Study. J Adv Chem Eng 6: 144. doi:10.4172/2090-4568.1000144

Page 8 of 8

27. Nares R, Ramirez J, Gutierrez-Alejandre A, Cuevas R (2009) Characterization and Hydrogenation Activity of $\mathrm{Ni} / \mathrm{Si}(\mathrm{Al})-\mathrm{MCM}-41$ Catalysts Prepared by Deposition-Precipitation. Ind Eng Chem Res 48: 1154-1162.

28. Zhao X, Wei L, Cheng S, Huang Y, Yu Y, et al. (2015) Catalytic cracking of camelina oil for hydrocarbon biofuel over ZSM-5-Zn catalyst Original. Fuel Process Technol 139: 117-126.

29. Madsen AT, Rozmyszowicz B, Simakova IL, Kilpio T, Leino AR, et al. (2011) Step Changes and Deactivation Behavior in the Continuous Decarboxylation of Stearic Acid. Ind Eng Chem Res 50: 11049-11058.

30. Hermida L, Abdullah AZ, Mohamed AR (2015) Deoxygenation of fatty acid to produce diesel-like hydrocarbons. Renewable Sustainable Energy Rev 42: 1223-1233.
31. Norhasyimi R, Zuhairi A, Abdul Rahman M (2010) Recent progress on innovative and potential technologies for glycerol transformation into fuel additives: A critical review. Renewable Sustainable Energy Rev 14: 987-1000.

32. Ullah K, Ahmad M, Sultana S, Teong LK, Sharma VK, et al. (2014) Experimental analysis of di-functional magnetic oxide catalyst and its performance in the hemp plant biodiesel production. Applied Energy 113: 660-669.

33. Wolfson A, Yefet E, Alon T, Dlugy C, Tavor D (2015) Glycerolysis of Esters with Candida antarctica Lipase B in Glycerol. J Adv Chem Eng. 